\title{
Detection of staphylococcal enterotoxin in gastric juice
}

\author{
N. DICKIE, C. E. PARK, AND H. ROBERN \\ From the Bureau of Microbial Hazards, Food Directorate, Health Protection Branch, \\ Health and Welfare Canada, Ottawa (Canada)
}

SYNOPSIS The gastric juice of a patient showing symptoms of staphylococcal food poisoning was examined by a radioimmunoassay for the presence of enterotoxins. Assays gave markedly higher results at $35^{\circ}$ than at $5^{\circ}$. The source for this discrepancy was attributed to interference due to trypsin activity on the basis of (1) the demonstration of hydrolysis of $p$-toluenesulfonyl-L-arginine methyl ester by the specimen, (2) inhibition of this activity by trypsin inhibitor from lima bean, and (3) lowered values produced for enterotoxins in gastric juice when the inhibitor was included in the assay system.

In episodes of staphylococcal food poisoning, where the suspected food is not available for analysis, tests for the presence of staphylococcal enterotoxin in gastric juice of patients may serve as a useful alternative. Rapid radioimmunoassays have been described for detection of staphylococcal enterotoxin types A, B, and C (Johnson et al., 1971; Collins et al, 1972; Collins et al, 1973; Dickie et al, 1973). However, our previous efforts to measure staphylococcal enterotoxin in stomach aspirate by radioimmunoassay (RIA) were unsuccessful since positive results were not corroborated by the microslide immunodiffusion test (Casman et al, 1969). These attempts were expanded in the present study.

\section{Material and methods}

STAPHYLOCOCCAL ENTEROTOXINS

Purified enterotoxin $A$ and rabbit antiserum were prepared in this laboratory (Robern et al, 1975). Enterotoxin $B$ and rabbit antiserum were from Makor Chemicals Ltd (Jerusalem). According to the manufacturer, the toxin was homogeneous in the analytical ultracentrifuge and by electrophoresis. Purified enterotoxin $C_{1}$ (Borja and Bergdoll, 1967) and rabbit antiserum were kindly made available to us by Professor M. S. Bergdoll, Food Research Institute, the University of Wisconsin (Madison).

\section{RADIOIODINATION}

Enterotoxin was trace-labelled with ${ }^{125}$ I to a specific Received for publication 18 February 1976 activity in the range 0.5 to $1.0 \mathrm{~g}$-atom per mole, according to the method of Thorell and Johansson (1971). Iodide was separated from iodinated protein by filtration through a column of Sephadex G-100 which was equilibrated with saline-buffer (see below).

\section{RADIOIMMUNOASSAY}

Enterotoxin was assayed following the principles of Catt and Tregear (1967), as modified by Ceska et al (1970). The procedure, adapted for this study from previous work (Dickie et al, 1973), was as follows: antibody-coated tubes were prepared by incubating polystyrene test tubes (Falcon) overnight at $35^{\circ}$ with $2.0 \mathrm{ml}$ of a 1:10000 dilution of antiserum in 0.1 M carbonate-bicarbonate buffer ( $\mathrm{pH}$ 9.6), after which the tubes were washed with $0.9 \%(\mathrm{w} / \mathrm{v})$ sodium chloride. Standard toxin solutions were prepared by diluting a portion of the stock standard to concentrations of $0.63-10 \mathrm{ng} / \mathrm{ml}$ with $0.05 \mathrm{M}$ phosphate buffer (pH 7.4), $0.15 \mathrm{~m}$ sodium chloride, $0.05 \%(\mathrm{w} / \mathrm{v})$ sodium azide, $0.05 \%(\mathrm{w} / \mathrm{v})$ Tween 20 , and $0.5 \%$ (w/v) bovine serum albumin (Sigma lot no. 43C2300). The gastric aspirate was diluted with the same solvent giving dilutions of $36,72,144$, and 288 fold. The usual assay mixture consisted of $125 \mathrm{I}$-enterotoxin (about 50000 counts $/ \mathrm{min}$ ) and $1.0 \mathrm{ml}$ of standard toxin or diluted aspirate in a final volume of $1.5 \mathrm{ml}$. After incubation at $35^{\circ}$ or $5^{\circ}$ for 16 hours the tubes were washed twice with tap water and count rates were measured in a gamma counter. The correction for non-specific bound counts/min (less than $0.5 \%$ 
of the total radioactivity) was determined after incubation in uncoated tubes in the absence of unlabelled toxin. The ratio of bound to total radioactivity for ligand at zero dose was in the range of $0 \cdot 15$ to $0 \cdot 20$. The dose-response curve for standard toxin was

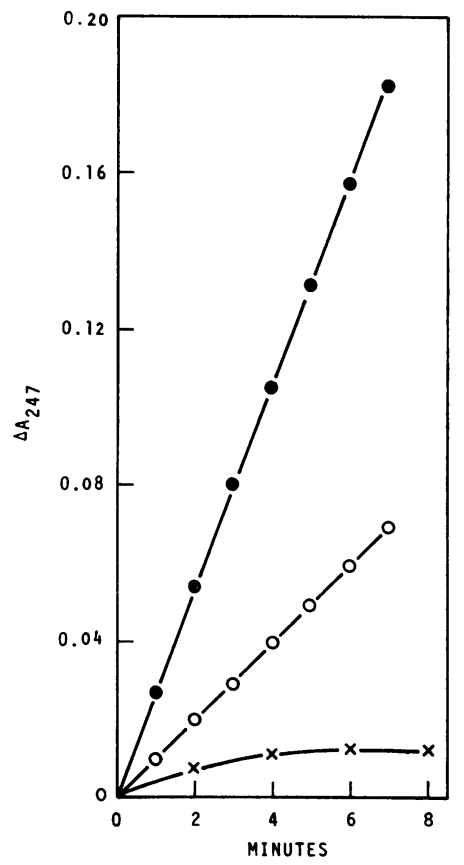

Fig 1 Hydrolysis of $\mathrm{p}$-toluenesulfonyl-L-arginine methyl ester by stomach aspirate: $70 \mu l(0), 30 \mu l(O)$, $30 \mu l$ plus $1 \mathrm{mg}$ lima bean trypsin inhibitor $(x)$. linearized using the relationship logit $\left(B / B_{0}\right)=\frac{7}{5}$ $a+b \log (x)$ (Rodbard et al, 1969). Values for ' $a$ '으 and ' $b$ ' were obtained by unweighted least squares $\Rightarrow$ regression (Magar, 1972).

\section{TRYPSIN ACTIVITY}

This was assayed using $p$-toluenesulfonyl-L-arginine $\frac{\widehat{D}}{\widetilde{\sigma}}$ methyl ester according to the procedure in 'Worth- $\varrho$ ington Enzymes Reagents', Worthington Biochemical Corp, Freehold, New Jersey.

\section{Results and discussion}

A stomach aspirate was obtained from a 21-year-old woman showing symptoms typical of staphylococcal? enterotoxicosis. Approximately $5 \times 10^{5}$ viablexo Staphylococcus aureus organisms were found pere millilitre. Five Staph. aureus colonies were subcultured for further tests. Tests for enterotoxin typeso A, B, C, D, and E by the microslide method showed? that only one isolate of Staph. aureus produced enterotoxin (type A) in culture. RIA carried out ato $35^{\circ}$ gave strongly positive results (about $10 \mu \mathrm{g} / \mathrm{m} \mathbb{D}^{+}$ aspirate) for each of the enterotoxins (types $A, B \frac{3}{0}$ and $\mathrm{C}_{1}$ ) tested but assays at $5^{\circ}$ led to five-fold lower@ values. Analysis of the aspirate by the microslidemethod, which in our hands can detect 0.5 gg toxin/ml, gave a negative result for each to: $\left(\mathrm{A}, \mathrm{B}, \mathrm{C}_{1}\right)$.

A possible reason for these results was suggesteds by the presence of trypsin activity in the specimen, (fig 1). In the following experiments, trypsin inhibitoo from lima bean (Worthington) was added to the assay tubes at zero time at the previously determine 6

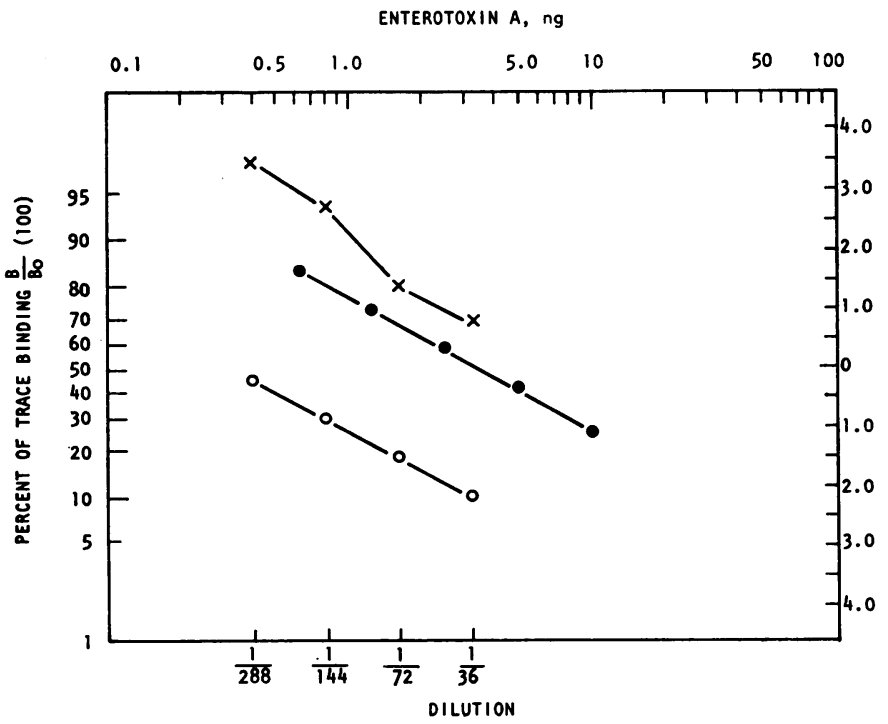

Fig 2 Inhibition of binding of ${ }^{125} \mathrm{I}$ enterotoxin $A$ to rabbit antiserum by enterotoxin $A$ and stomach aspirate. enterotoxin $A(O)$, stomach aspirate (O), stomach aspirate plus lima

(+) bean trypsin inhibitor added at $1 \mathrm{mg} / \mathrm{ml}$ of $1: 36$ dilution $(x)$. Each point is the average of two - determinations (SE for average bound counts $/ \mathrm{min} \cong 5 \%$ ) using $1.00 \mathrm{~N}$ $\mathrm{ml}$ of serial dilution of standard toxinn or stomach aspirate. The temperature of incubation was $5^{\circ}$. The presence $\omega$

(-) of lima bean inhibitor in enterotoxing solutions (0.5 mg:10 ng toxin) did not alter the characteristics of the standard curve. 
ratio ( $1 \mathrm{mg}: 30 \mu \mathrm{l}$ aspirate) to yield complete inhibition of the trypsin activity in 4 minutes (fig 1). A shift in the dose-response curve for enterotoxin $A$ (fig 2) and B (not shown) to the low-dose region of the standard curve was seen, giving values of 0.07 and $0.05 \mu \mathrm{g} / \mathrm{ml}$, respectively. For the same dilution range, the dose-response curve for enterotoxin $C_{1}$ in assays using inhibitor was shifted beyond the detection limit of the assay, which usually occurs at about $90 \%$ B/B $\mathbf{B}_{0}$ (Rodbard et al, 1969). A similar effect was seen in assays at $5^{\circ}$ comparing untreated and heat-treated (for 10 minutes at $80^{\circ}$ ) specimens, but values were further reduced (eg, $0.03 \mu \mathrm{g}$ enterotoxin $\mathrm{A} / \mathrm{ml}$ and no detectable type $\mathrm{B}$ or $\mathrm{C}_{1}$ ). These findings can be explained by assuming the digestion of antibody and/or antibody-125I-toxin complexes by trypsin activity, giving erroneously low values for ${ }^{125}$ I-activity bound to antibody. On the other hand, positive results for enterotoxin in the presence of trypsin inhibitor, or after heat-treatment, were interpreted as reflecting the presence of enterotoxinproducing Staph. aureus in the specimen. With the latter treatment, some loss due to thermal inactivation of toxin is expected. It seems that RIA might have some merits in the analysis of gastric juice for enterotoxin. However, it is evident that interference by proteinase should be considered when such specimens are examined. A problem encountered in the detection of hepatitis B virus in human faeces and bile has also pointed to the involvement of proteolytic enzymes (Moodie et al, 1974).

We thank Mr. Y. Yano for expert technical assistance.

\section{References}

Borja, C. R. and Bergdoll, M. S. (1967). Purification and partial characterization of enterotoxin $C$ produced by Staphylococcus aureus strain 137. Biochemistry, 6, 14671473.

Casman, E. P., Bennett, R. W., Dorsey, A. E., and Stone, J. E. (1969). The micro-slide gel double diffusion test for the detection and assay of staphylococcal enterotoxins. Hlth Lab. Sci., 6, 185-198.

Catt, K. and Tregear, G. W. (1967). Solid-phase radioimmunoassay in antibody-coated tubes. Science, 158 , 1570-1572.

Ceska, M., Grossmüller, F., and Lundkvist, U. (1970). Solid-phase radioimmunoassay of insulin. Acta endocr. (Kbh.), 64, 111-125.

Collins, W. S., II, Metzger, J. F., and Johnson, A. D. (1972) A rapid solid phase radioimmunoassay for staphylococcal B enterotoxin. J. Immunol., 108, 852-856.

Collins, W. S., II, Johnson, A. D., Metzger, J. F., and Bennett, R. W. (1973). Rapid solid-phase radioimmunoassay for staphylococcal enterotoxin A. Appl. Microbiol., 25, 774-777.

Dickie, N., Yano, Y., Park, C. E., Robern, H., and Stavric, S (1973) Solid-phase radioimmunoassay of staphylococcal enterotoxins in food Staphylococci in Foods Conference, Pennsylvania State University, University Park, Pa., March 18-20, pp. 188-204.

Johnson, H. M., Bukovic, J. A., Kauffman, P. E., and Peeler, J. T. (1971). Staphylococcal enterotoxin B: solid-phase radioimmunoassay. Appl. Microbio!., 22, 837-841.

Magar, M. E. (1972). Data Analysis in Biochemistry and Biophysics, pp. 102-104. Academic Press, New York and London.

Moodie, J. W., Stannard, L. M., and Kipps, A. (1974). The problem of the demonstration of hepatitis B antigen in faeces and bile. J. clin. Path., 27, 693-697.

Robern, H., Stavric, S., and Dickie, N. (1975). The application of QAE-Sephadex for the purification of two staphylococcal enterotoxins. II. Purification of enterotoxin A. Biochint. biophys. Acta (Amst.), 393, 159-164.

Rodbard, D., Bridson, W., and Rayford, P. L. (1969). Rapid calculation of radioimmunoassay results. J. Lab. clin. Med., 74, 770-781.

Thorell, J. I. and Johansson, B. G. (1971). Enzymatic iodination of polypeptides with ${ }^{125}$ I to high specific activity. Biochim. biophvs. Acta (Amst.), 251, 363-369. 